\title{
黑人科家和㥅明家
}

\section{亞普塞克著 梅亦朢譯}

在生活的領域裹, 涩有比科學生活方面更好

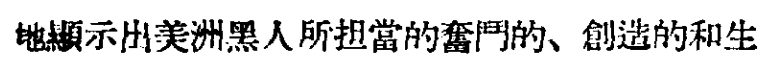

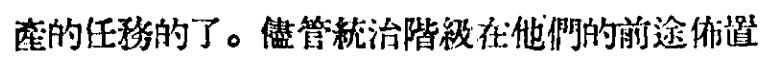
了那末多的障礙, 黑人在科學方面的貢噳是文多 又重要的。

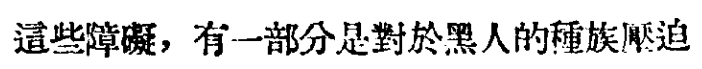
的必然的結果, 而更因筇不諭男女的黑人的科學 工作者的和現，對於目目地攱視和排斥黑人的那

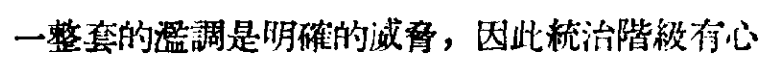
地製造了許多障礙。並且，黑人掌握了科學，就盗强 了勇策，缉他們的解放鬥孚供給了武器。而科學 是和社會現筫漸接在一起的, 這一程觀默就帶来 了一連串關於被剩例階級或是被統治的人民的科 學的問題, 使他們不得不慗求因㢣的統治階級來 正顥景些問題。

在造些障礙之中, 必須要稍加說明的是二百 五十年以來，90\%的美洲黑人，是“合法”的奴

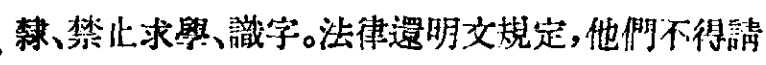
求發明的尃利。當然, 這並不是說因此汥有些黑

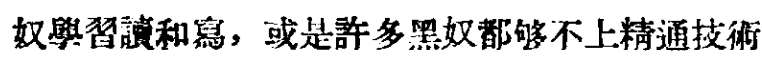
或機峨的高敉水平; 這也证不表示在“自由”黑人 之間 (1860 年時, “自由”黑人約有 500,000 人) 浔有培育出出色的科學家和發明家來, 而望在是

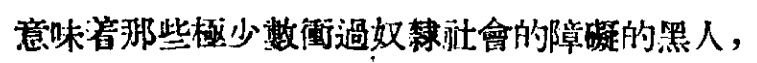

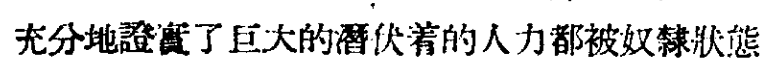
給可怕地遏制着而摧毁了。

由於奴隸制度的消堿以及施會上一般的，比 其是黑人的生虐力的增加，眼見得就荘壮現科學

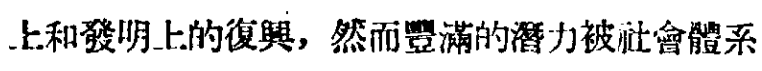
的㓥削本質，尤其是吉姆 - 克羅 (Jim Crow, 專䍀從事迫害黑人的種族諭者的總称一一譯者) 對於黑人的特殊的怚厚給降低了。在 1870 年, $80 \%$ 以上的黑人不能瀘和竄; 而屝至 1910 年,
十藏以上的黑人當中, 仍然有三分之一的人從将

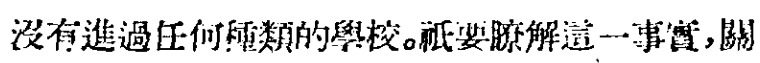

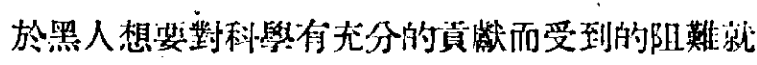
可以得到一種大略的慨念了。

在简略地檢討美洲黑人對於科學上.瑅大的光

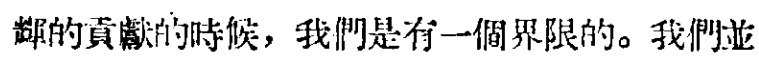

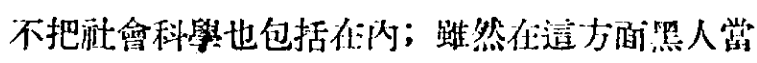
中曾經㡾生了像杜波例博士 (Wr. E. B. Da Bois) 或是已故的伍特生博士 (C. G. Woorlson) 那樣的 世界閏名的大科學家。我們也不打算到像前一

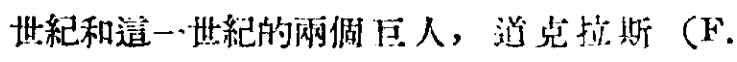

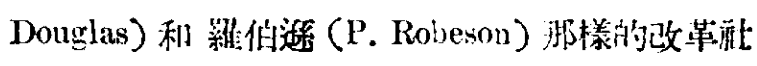
會的科學家。

都不是，我們只叙述自然科學家和墢昫家一 经了人類的幸㖇, 製造或發現增州人類支配自然 的能力的工具或方法的創造者和㻐現者。品人在 这方面的成就是很卓越的, 但所得到的却是調刺。

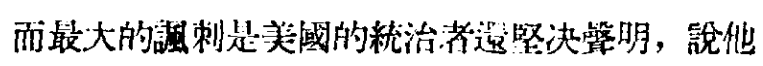

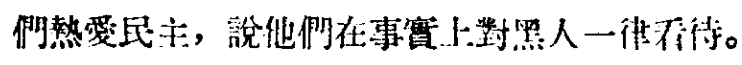

同樣的，我們所要陳述的都旮涩着滍刺，從

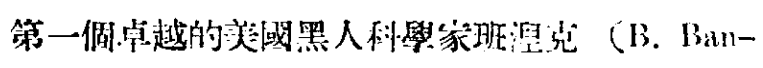

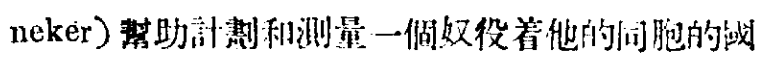
家的首都的時俣起, 一近到卡佛 (G. W. Cirrver)

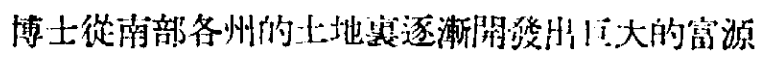

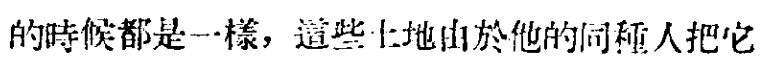

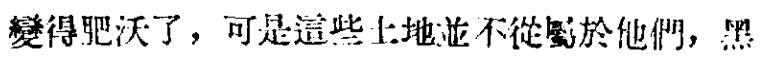

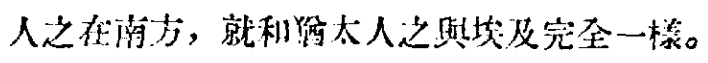

看看卡年则月裹遭㮖死的 45 藏的朱F鲁 (C.

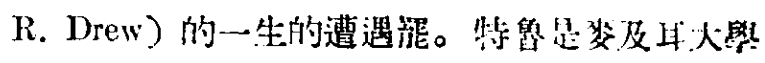

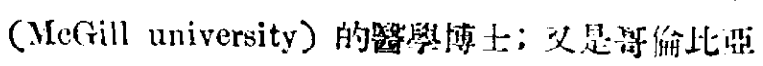

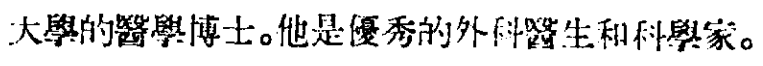

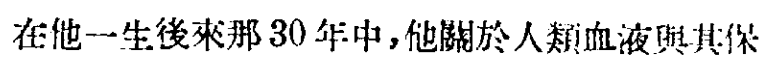



魏斯曼一一摩根生物學尤其是基因學說的打教。 遗一工作踓然與葆聯的生物學家米邱林和李森科

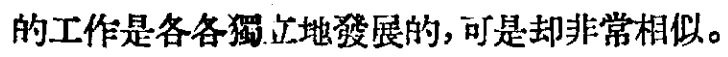

吉斯特博士堅持,而他的工作也表明了,那種 “生殖䋚胞是與其他體細胞完全獨立”的摡念是錯 誤的，他堅决主張緗胞㤥和細胞質之間的相互依 赖和相互作用，並且强調環境的重要性，他堅持生 活的榙證的本質。他說:

“自行調管，自行分化，是生活物質組成的基 本表現，……不諭我們研究原子，或是星星， 或是活的物質，我們必須隨時記任相互作用， ……踓然我們從整個自然當中提取各種門颣 成管相互隔耀的領域, 但自然的整體一致是 你在着的。

某些沪渝吉斯特博士的人，聲䊈他的反對基

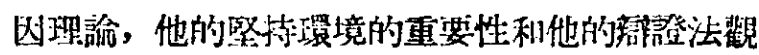
點都是起源於他對的族論的“偏見”一一遥就是由

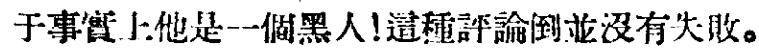

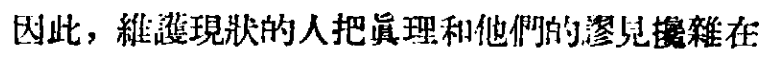
一起了。而資產階級“客觀性”的宜停者渠法了解

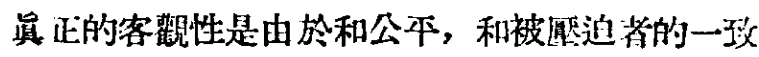

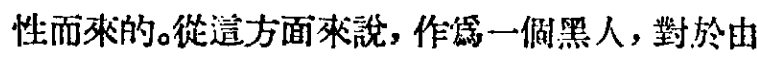

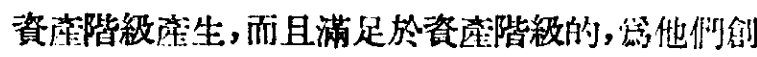
造、挴育和支持的程族論的生物學, 吉斯特博士 江刻很合適地對之發生了情鼠。

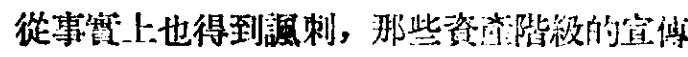

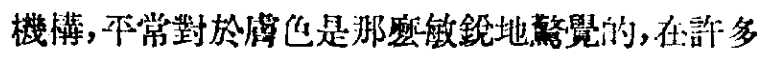

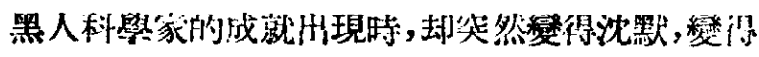

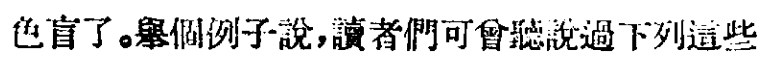
人的事落嗎?

特納槽士 (T. W. Turner), 漢普敦研笑所 (Hampton Institute) 生物部主任,美國科學進生 協會 (American Association for the advancement of Science) 會員, 研究金等榮養物筫對於 種子植物的效應和棉花序種的先進者。

派克博士 (C. S. Parker) 篗蓝徳大學植物系 主任, 39 種植物新種的發現渚。

倍烈博士 (L. H. Berry) 胃汒分析和胃的生 物化學的卓越的權威。

乫頓博士 (W. A. Hinton), 細菌學和叒疫

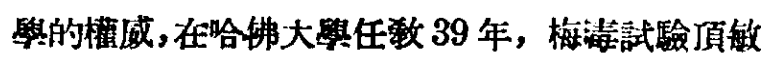

鈆的試驗方法一一梁頓社驗的創造人。

格林奈 (H. J. Greene) 可塑物研究的前驅

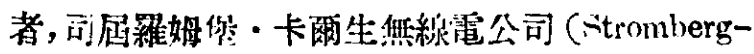
Carlson Ralio Corporation) 可塑物研究部的专 任。

哈立斯博士（E． L. Harris）噴篓飛機和火 箭炮燃料的第一流權威，拉特・柏特生瓜機場 (Wright Patterson Air Field) 噴莱珴機和火箭 炮研究空主任。

特納博士 (C. H. Turner) 動物與鼠越, 尤其

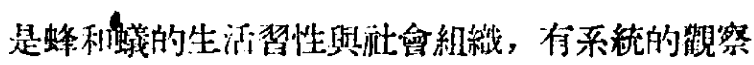
的創始人。

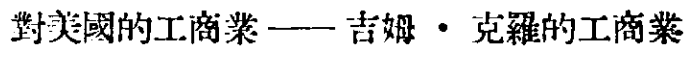
一一照人科學家和發明家也作了最偉大的；壉，

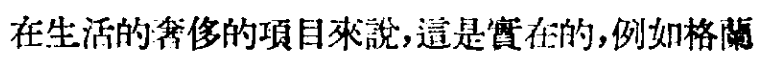
特 (G. F. Grant) 破明了第自動踇琴用的“构球 座”(Golf tee) 後來由迪更生(J. H. Dickinson)

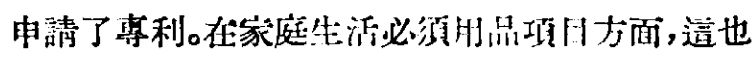
是管在的, 例如斯蒂太特 (T. S. Stewart) 發朋 了拖把柄 (mop-holder)。再就對美國的大部分 $\mathrm{L}$

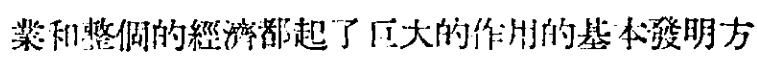
面来說，那也是旨筑的。

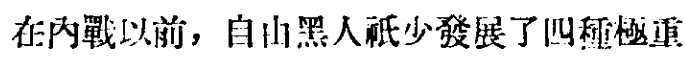
妿的登明, 最与是福教 (.J. Forten), 菲城的主荘

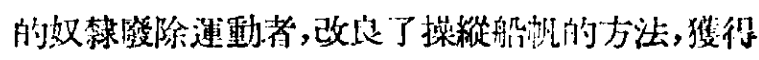

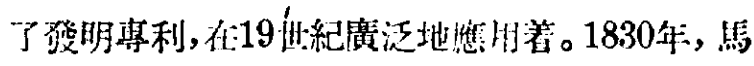
利策(Maryland)地方的几莱（II. Blair) 發明了

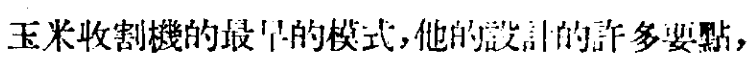
隼用了好戠代。

十一年以後哂待新裴德湢(New Bedford)地方

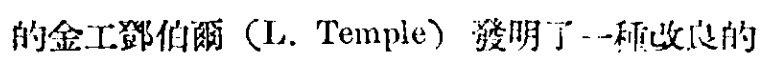

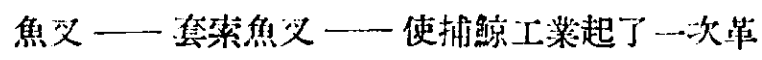

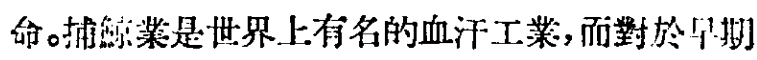

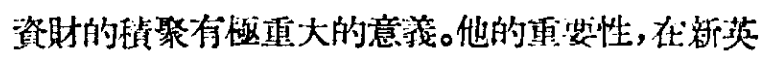

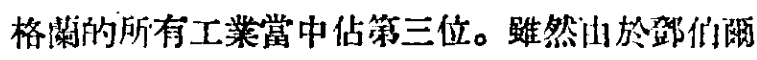

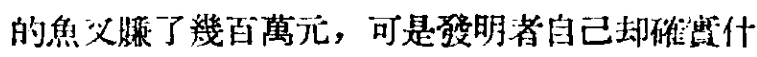

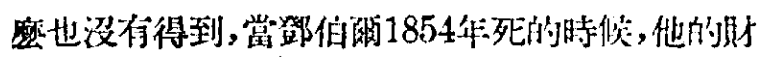

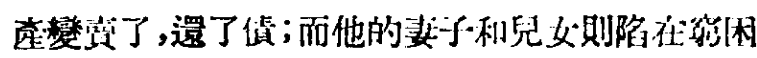
的境地。

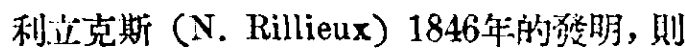

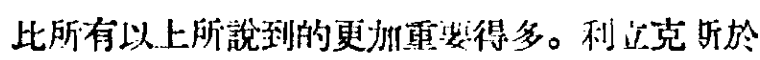
1806年生在新奥爾良城中小康的黑人家裂，他在 
巴黎然替機栈工程。40棫時他回到路易斯安 那

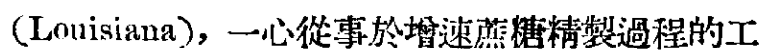
作。他發明了一種多效蒸發器, 解决了問題, 亚且

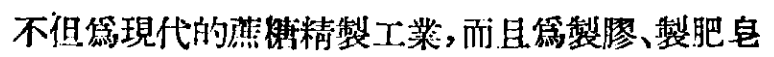

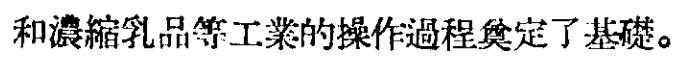

但是在斯配黑奴的路易斯安那州（當時南北 戰留沿末閒始, 南部黑人連名義上的解放都還沒 得到。一譯者) 的生活,對於利立克斯急來愈不 能忍受, 因此1850年他回到法咸, 媵隶就死在法 國。在今日的吉姆・克羅的新奥爾良城的路易斯 安那州博物舘, 還有一塊碑, 表示對利立克斯的 拿敬,上面的銘文說:

\section{第了尊敬和紀念}

楛貝特・利克克斯

1806年3 月18日生於路易斯安那州新奥爾良城 1894年10月 9 日死於法域巴黎*

多效蒸發器的發明人证已應用於製淒工業 此碑由全世界彆媇工業協會設立於1934年

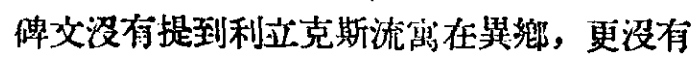
予以解釋。

在南北戰净以媵, 很少工菜是汥有黑人科學 和發明的天才的激捱而生長和㗶展起來的。例如 保藏肉類以及易于留敗食物的工業, 完全應㽬歸 功於霍爾(L.A. Hall)博士。他筸獲得8種專利。30 年前他是美國陸軍爆炸物首席助理檢查官。以後 霍爾博士一心政力於食物調味方面的工作，尤其

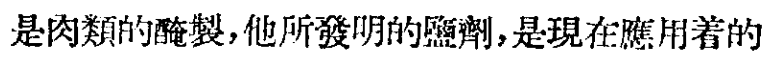
頂使人䩗意的一種, 侕且在整倜行業當中應用着。 還有, 例如化學家渮获 (W. G. Holly)發明了一種 超等的油漆, 所調鈦光澢(titanium gloss Paint),

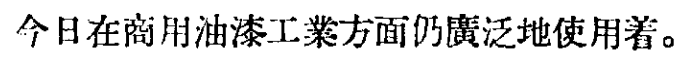

在治金學方面，工程㸬派生 (J. A. Parson) 和物理學家任姆斯 (E. S. Imes) 的工作是非常 優越的。派生發現了一種很有用的鋁銅合金, 而對 於金第等蚛方面也完成了有意義的研究工作, 當

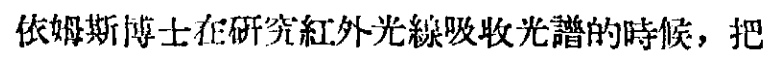
它隹用來籼断合金的缺點, 這是很值得注意的一 種應㭢。

黑人的發明在捕鯨業和製㜍工業上起了革 命, 而在製鞋工業上:也是一樣, 這異我們必須提到 馬滋利格(J. E. Matzeliger)的工作。
馬滋利格是在菲城和林 (Lynn) 唯工 的鞋近,後來在1889年,他37筬的時候死於貧困的 生活。早在1883年，這位黑人的工留級的大猚 得了一種複雜的鞋型機器的專利。这是從听朱有 的第一偑機械, 它能在鞋型.上撌任一隻鞋了, 然後 抓任皮革, 把它沿着鞋後跟扯一來, 把它絴佳, 最 後添出完全製好了的鞋子。

這一專利媵來以極少量的金踐償給了聯合製

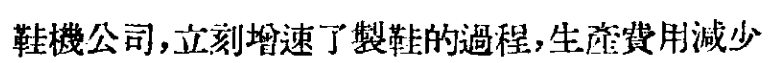
了一牛, 且趿成了聯合製鞋公司成答世界上第一 流的價值千百萬的企業公司和㳏少數的百分之一 百的專利公司之一。

前面已經提起過了, 馬滋利格在發明了造一 機械的六年以後窥困的死了。所有他得到的祇是 他知道了一件事賷, 就是說, 他的發明已使一種基 本工業改憼, 而他的唯一的 “紀念” 是在整偑美國 慗鞋工業震, 他的機器以一個早污的種族跂視者 的字眼稱呼着。

在電機和交通工業方面, 黑人也有重要的發 現。在這方面侍許多由爱迪生請求專利的基本的 碎明, 其望都是愛迪生的同事的研究工作的集合 起來的成果。黑人賴鐵謀 (L. H. Latimer) 就是

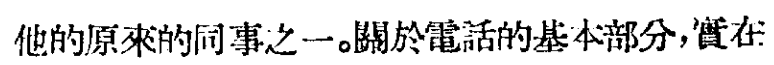
應核歸功於富有發明力的伍滋 (G. T. Woods)。证 在行進的火車, 能够相不收㷋電訊，也是伍滋的功， 勞。在電動火車鐵道方面, 對於“第三鐵軌”（thirl. rail) 的浴展, 他作了基本的建議。他還幫此指等

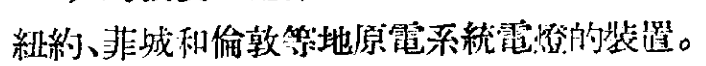

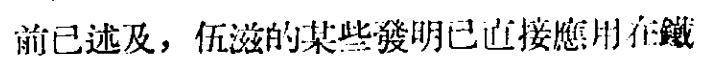

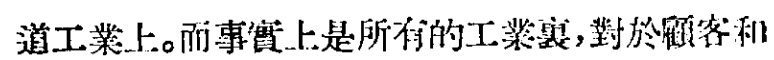

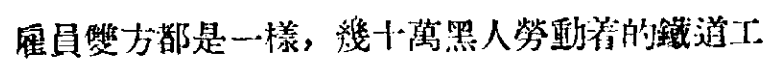
業**，或者可算得是所有吉姆・克雅賞中頂惡瑇 的, 而且是從黑人的科學工作當中獲益最多的工 萧。

同楛也是伍滋, 他發明了在鐵路上廣泛地使 用着的自動空氣制重秝幾。而逃灾的黑奴的兒子装

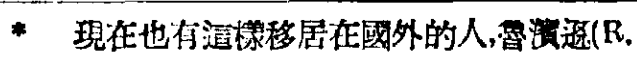
Robinson)就是㔨名的例子。他是生活在蘇聯 的美

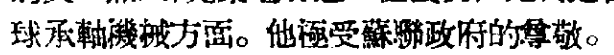

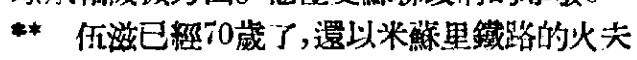
的職䅂工作清, 他在東方學替電機工程, 整在 國外的一艘英國船中任工程師。 


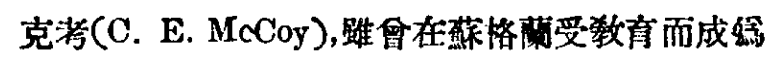
工程師, 可是在美國却被拒絕做相門㵶澲的工作， 而在密歇根中央鐡路做了好些年火夫。他在 1872 年, 得到了第一個䍃正在運動着的機械自動上油 的墢明的専利, 㯰一發明在全球火車利輪船上使 用着。

阿拉巴啀地方的皮埃特 (A. J. Beard) 任18 97 年得到火車自動赖鈎這一發明專利。闹一年, 另外一個黑人，芝加哥的鲁濱愿 (E. C. Robinson) 弡明了火車車輪的特方改良的䇺造方法 (美國火 車銀浩公司探用了遙一方法, 却汥有付出任何報 酬)。稍後, 他又墢明杏內電車的與架空線相接觸 的䭞輪。

芝加哥的另一黑人達蒙(W.H. Dammond), 創䌘了自動刹車信號系統 (稱学達習線路) 是安 全信號方面的基本創造, 例如在紐約地下電斗就 使用着。另外有蓋货車的冷却設嘴的工作是㻴斯 (F. M. Jones)完成的, 而黑人化學家海納斯 (W. G. Haynes) 創造了現在通用的保護枕木的液體。

80年以前，黑人酷生遭受着哥倫比亞區䇴學 會吉姆・克羅政策的经制, 在華盛頓成立了全國

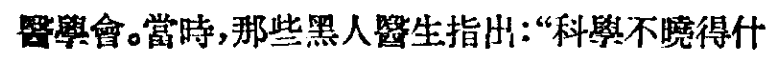
㦄種族，虐色或是身分”，因此他們公開“汉抗這種 野褋習性的遺鹠”。

但是這種野超的情况繼續存在着, 折磨着黑 人的繁生、工程家和科學工作者。所以，最要䇣的

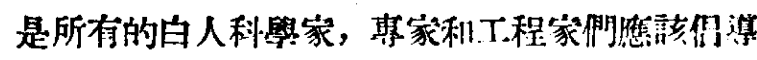
反對這程情况的運動, 而且必須在他們的国积该,

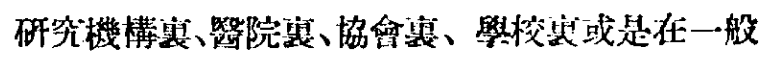

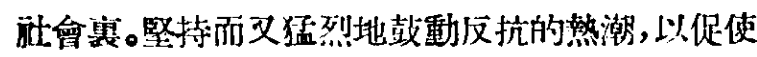
這程情形及早根絕。

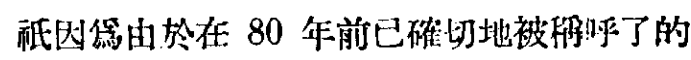
“野楚”，而願意看着科學不能授掦光大，人才浪

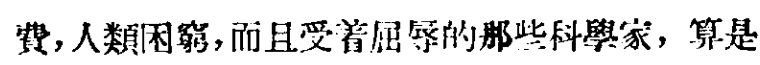
什䐴樣的科學家呢?

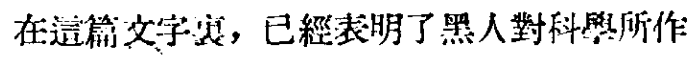

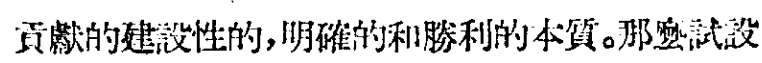

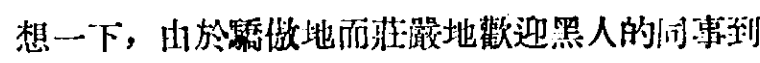

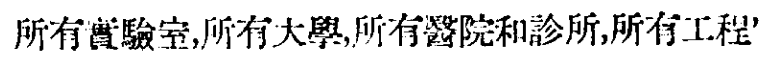

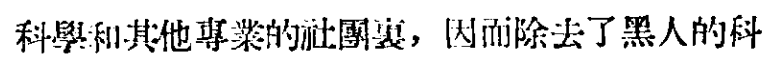

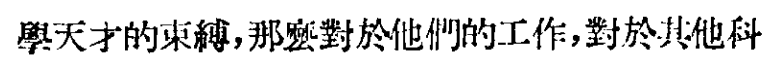
學家的工作，以及對於使科學服務於幸模與和本

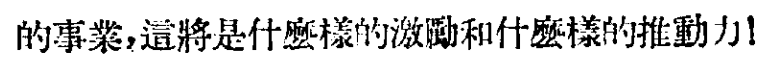

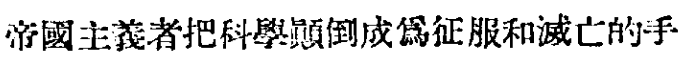
段。只有工人階級和他的盟友一一在美國，尤其是 一千七百萬的黑人, 需装科學, 需要作琈生活和解

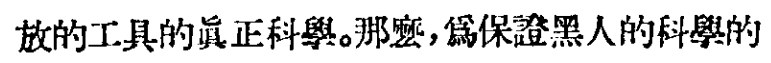

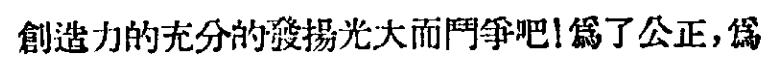

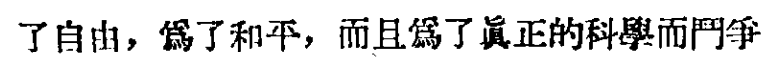
吅!

〔本交譯自“蛋兽與主流(Masses \& Mainstream)” 1951年2月號, 原題您“The Negro Scientists and Inventor", 作者䉆 Herbert Aptheker.]

\section{民主德國科學家希望與我國科學家直接通訊聯熬}

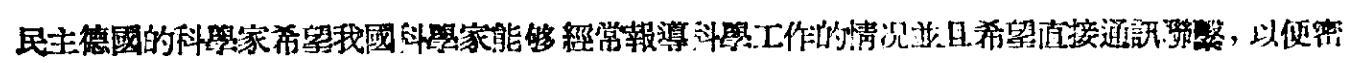

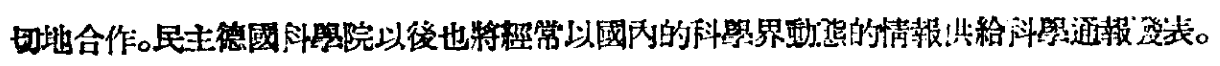

